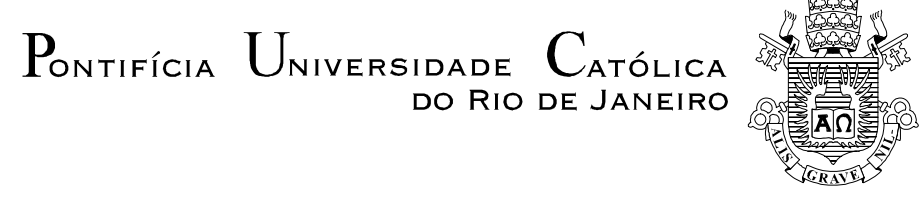

Romano José Magacho da Silva

Integração de um Dispositivo Óptico de Rastreamento a uma Ferramenta de Realidade Virtual

Dissertação de Mestrado

Dissertação apresentada como requisito parcial para obtenção do título de Mestre pelo Programa de PósGraduação em Informática da PUC-Rio.

Orientador: Prof. Marcelo Gattass Co-orientador: Prof. Alberto Barbosa Raposo

Rio de Janeiro, setembro de 2004 

Pontifícia Universidade $_{\text {Do Rio de Janélica }}$

Romano José Magacho da Silva

\title{
Integração de um Dispositivo Óptico de Rastreamento a uma Ferramenta de Realidade Virtual
}

Dissertação apresentada como requisito parcial para obtenção do título de Mestre pelo Programa de Pós-Graduação em Informática da PUC-Rio. Aprovada pela Comissão Examinadora abaixo assinada.

\author{
Marcelo Gattass \\ Orientador \\ Departamento de Informática - PUC-Rio
}

Alberto Barbosa Raposo

Co-orientador

Departamento de Informática - PUC-Rio

Waldemar Celes Filho Departamento de Informática - PUC-Rio

Paulo Cezar Pinto Carvalho Instituto Nacional de Matemática Pura e Aplicada (IMPA)

Flávio Szenberg Tecgraf - PUC-Rio

Prof. José Eugenio Leal Coordenador Setorial do Centro Técnico Científico - PUC-Rio

Rio de Janeiro, 31 de março de 2004 
Todos os direitos reservados. É proibida a reprodução total ou parcial do trabalho sem autorização da universidade, do autor e dos seus orientadores.

\section{Romano José Magacho da Silva}

Graduou-se em Engenharia de Computação no Instituto Militar de Engenharia (IME/RJ) em 1998. Trabalhou no Instituto de Pesquisa e Desenvolvimento do Exército no projeto de Comando, Controle e Informação, no desenvolvimento de ferramentas de informação geográfica. Nos anos 2000 e 2001, atuou como desenvolvedor da aplicação de Comando Tático de Manobra do Sistema de Artilharia do Exército na Indústria de Material Bélico do Brasil.

Ficha Catalográfica

Silva, Romano José Magacho da

Integração de um dispositivo óptico de rastreamento a uma ferramenta de realidade virtual / Romano José Magacho da Silva; orientador: Marcelo Gattass; co-orientador: Alberto Barbosa Raposo. Rio de Janeiro: PUC-Rio, Departamento de Informática, 2004.

76 f. : il. ; $30 \mathrm{~cm}$

Dissertação (mestrado) - Pontifícia Universidade Católica do Rio de Janeiro, Departamento de Informática.

Inclui referências bibliográficas

1. Informática - Teses. 2. Realidade virtual. 3. Visão computacional. 4. Dispositivo de rastreamento. I. Gattass, Marcelo. II. Raposo, Alberto Barbosa. III. Pontifícia Universidade Católica do Rio de Janeiro. Departamento de Informática. IV. Título. 
"Memento, homo, quia pulvis es, et in púlverem revertéris". Gn 3,19.

A Nosso Senhor Jesus Cristo, Rei dos reis e a Nossa Senhora, medianeira de todas as graças. 


\section{Agradecimentos}

A Deus, nosso Senhor Jesus Cristo, toda honra e toda glória.

A minha família, minha esposa, meus filhos, meus pais, meus irmãos e meus amigos pelo apoio, compreensão e paciência.

Ao orientador e professor Marcelo Gattass pelo conhecimento e apoio durante o curso.

Ao meu co-orientador, professor Alberto Barbosa Raposo, pelo apoio e pela amizade conquistada.

Aos dois, muito obrigado pela oportunidade de trabalhar e aprender em um tão conceituado grupo como o TeCGraf.

Aos colegas do TeCGraf que de algum modo ajudaram na realização deste trabalho, Felipe, Gustavo, Thiago, Márcio Henrique, Ricardo, Pedro Ponce, Eduardo Thadeu, Eduardo Teles, Manuel, Gabriel, Flávio Szenberg, Felipe Lobo, Pablo, Fred, César Pozzer, prof. Waldemar e a tantos outros que merecem muito mais do que um simples obrigado.

Ao colega de turma Ênio Russo que transmitiu uma invejável sabedoria e paciência, me ajudando a acalmar nos momentos de turbulência.

Ao Exército Brasileiro e ao Instituto Militar de Engenharia. 


\section{Resumo}

Silva, Romano J M.; Gattass, Marcelo (Orientador); Raposo, Alberto B (Coorientador). Integração de um Dispositivo Óptico de Rastreamento a uma Ferramenta de Realidade Virtual. Rio de Janeiro, 2004. 76p. Dissertação de Mestrado - Departamento de Informática, Pontifícia Universidade Católica do Rio de Janeiro.

Os sistemas de realidade virtual requerem dispositivos de interação que não obstruam o caráter imersivo da aplicação. Com a difusão das câmeras digitais, a captura óptica do movimento do usuário se firmou como uma nova área de pesquisa. Este trabalho apresenta a integração de um dispositivo óptico para interação em uma ferramenta de desenvolvimento de aplicações em realidade virtual. O dispositivo óptico proposto é composto por uma esfera revestida de material retroreflexivo rastreada por quatro câmeras com sensores infravermelhos. O estudo engloba a implementação do dispositivo de rastreamento óptico e sua integração com a ferramenta ViRAL (Virtual Reality Abstraction Layer).

\section{Palavras-chave}

Realidade-virtual, dispositivo de rastreamento, visão computacional. 


\section{Abstract}

Silva, Romano J M.; Gattass, Marcelo (Supervisor); Raposo, Alberto B (Cosupervisor). Integrating an Optical Tracking Device with a Virtual Reality Toolkit. Rio de Janeiro, 2004. 76p. M.Sc. Dissertation Departamento de Informática, Pontifícia Universidade Católica do Rio de Janeiro.

Virtual reality systems require tracking devices that do not harm the application immersive sensation. With the spread of digital cameras, the optical tracking of users' movement has been firmed as a new area of research. This work presents the integration of an optical tracking device with a virtual reality application development library. The proposed optical device is composed of a sphere coated with retroreflexive material, which is tracked by four cameras with infrared sensors. The study contains the implementation of the tracking device and its integration with ViRAL (Virtual Reality Abstraction Layer) tool.

\section{Keywords}

Virtual reality, tracking devices, computer vision. 


\section{Sumário}

1 Introdução 13

1.1. Objetivo 14

1.2. Organização da Dissertação 15

2 Realidade Virtual 16

2.1. Sistemas de Realidade Virtual 17

2.2. Dispositivos de Rastreamento 18

2.3. Ferramentas 25

3 Rastreamento 38

3.1. Calibração da câmera 40

3.2. Pré-processamento 45

3.3. Extração de elipses $\quad 48$

3.4. Posicionamento da esfera rastreada $\quad 50$

3.5. Filtro de Kalman

3.6. Algoritmo Proposto 55

4 Implementação e Resultados $\quad 56$

4.1. Implementação

4.2. Resultados 63

5 Conclusão

$\begin{array}{ll}\text { 5.1. Trabalhos Futuros } & 72\end{array}$

6 Referências Bibliográficas $\quad 73$ 


\section{Lista de figuras}

Figura 1: Ambientes de RV: (i) um capacete de RV; (ii) uma CAVE. 13

Figura 2: Dispositivos eletromagnéticos: (i) FasTrack e (ii) Flock of Birds. 19

Figura 3: Sensor de dobra. 20

Figura 4: Dispositivos mecânicos: (i) Phantom da Sensable e (ii) mão mecânica da EXOS. 20

Figura 5: Interseção entre duas esferas (um círculo) e entre três (dois pontos). 21

Figura 6: Dispositivos acústicos: (i) Logitech Tracker e (ii) FarReach. 22

Figura 7: Dispositivos inerciais: (i) 3D-Bird e (ii) Intertrax2. 23

Figura 8: DragonFly - dispositivo óptico desenvolvido pelo Instituto Fraunhofer de Engenharia Industrial da Alemanha. 24

Figura 9: LaserBird da Ascension Technology: sensor e feixe de laser. $\quad 24$

Figura 10: Classes de dispositivo do VRJuggler. 26

Figura 11: Hierarquia de classes de aplicação do VRJuggler. 27

Figura 12: Interface de criação de janelas no ViRAL. 31

Figura 13: Configuração de uma luva de RV no ViRAL. 32

Figura 14: Interface de conexão de eventos no ViRAL. 35

Figura 15: HMD rastreado por esferas retroreflexivas. 39

Figura 16: Esferas retroreflexivas: (i) Câmera convencional; (ii) Câmera com filtro infravermelho em ambiente com lâmpadas incandescentes; (iii) Câmera com filtro infravermelho em ambiente com lâmpadas fluorescentes.

Figura 17: Modelo de câmera "pinhole". 41

Figura 19: Distribuição gaussiana unidimensional com média 0 e $\sigma=1 . \quad 46$

Figura 20: Distribuição gaussiana bidimensional com média $(0,0)$ e $\sigma=1 . \quad 46$

Figura 21: Aproximação discreta da função gaussiana com $\sigma=1.47$

Figura 22: Filtragem gaussiana: (i) imagem original; (ii) filtro gaussiano. 47

Figura 23: Segmentação: (i) imagem original; (ii) imagem invertida; (iii) imagem $\begin{array}{ll}\text { segmentada } & 48\end{array}$

Figura 24: Duas componentes conexas baseado na 4-conectividade. 49 
Figura 25: Duas retas não paralelas no espaço. $\mathrm{O}$ vetor $w_{c}$ é o vetor de menor comprimento entre elas. $\quad 51$

Figura 27: Janela principal do programa de calibração. 56

Figura 28: (i) Padrão de calibração; (ii) interface de aplicação de filtros. $\quad 57$

Figura 29: Interface de calibração: identificação das esferas vistas por duas câmeras distintas.

Figura 30: (i) Imagem capturada da esfera sendo rastreada; (ii) Esfera rastreada inserida em um modelo virtual. $\quad 58$

Figura 31: Interface de configuração do plugin do dispositivo óptico. 59

Figura 32: Execução do plugin de cena no ViRAL. 62

Figura 33: Modelo esquemático do local de testes. 63

Figura 34: Teste 1 - Esfera em $\mathrm{Z}=12$ e câmeras calibradas com 10 pontos. 63

Figura 35: Teste 2 - Esfera em $Z=12$ e câmeras calibradas com 121 pontos. 64

Figura 36: Esfera em $Z=12$ e filtro de Kalman habilitado. 65

Figura 37: Teste 5 - Esfera em $Z=55$ e câmeras calibradas com 10 pontos. 67

Figura 38: Teste 6 - Esfera em $Z=55$ e câmeras calibradas com 121 pontos. 67

Figura 39: Esfera em $Z=55$ e filtro de Kalman habilitado. 68

Figura 40: Esquemático do movimento da esfera. $\quad 69$

Figura 41: Esfera se movimentando em $X$ e depois $Y$. 70

Figura 42: Esfera se movimentando em $X$ e depois $Y$ com filtro de Kalman habilitado. 70 


\section{Lista de tabelas}

Tabela 1: Função main de uma aplicação utilizando o VRJuggler. 28

Tabela 2: Vantagens e desvantagens do VRJuggler. 29

Tabela 3: Interface da classe vral::Device. 32

Tabela 4: Interface das classes vral::Scene e vral::SceneObject. 33

Tabela 5: Exemplo de uma cena simples criada no ViRAL. 34

Tabela 6: Plugin de cena com métodos de gravação e leitura de arquivo. 36

Tabela 7: Vantagens e desvantagens do ViRAL. 37

Tabela 8: Erros obtidos utilizando câmeras virtuais. 58

Tabela 9: Altura e distância focal obtidas pela calibração das câmeras. $\quad 59$

Tabela 10: Classe CaptureDevice. 60

Tabela 11: Pseudo-código do método track da classe Tracker. 60

Tabela 12: Classe TrackScene de um plugin de cena. $\quad 61$

Tabela 13: Classes TrackableObject de um plugin de cena. 62

Tabela 14: Posição média e desvio padrão dos testes 1,2, 3, 4. 66

Tabela 15: Posição média e desvio padrão dos testes 5, 6, 7, 8. 69 
Uma noite eu tive um sonho...

S Senhei que estava andando na praia com o minha vida. Para cada cena que se passava, percebi que eram deixados dois pares de pegadas na areia, um era meu e outro era do Senfor. Quando a última cena da minha vida passou diante de nós, olhei para trás, para as pegadas na areia, e notei que muitas vezes no caminho da vida havia apenas um par de pegadas na areia. Notei também que isto aconteceu nos momentos mais dificeis e angustiosos do meu viver. Isso me aborreceu, então perguntei ao Senfor:

- "Senfor, Tu me disseste que ao te seguir, Tu andarias sempre comigo, em todo o meu caminho, mas notei que durante as maiores tribulações do meu viver, havia apenas um par de pegadas na areia. Nõo compreendo porque nas horas em que necessitava de $\mathcal{T} i$, Tu me deixaste..."

O Senhor respondeu:

- "Meu precioso filho, Eu te amo e jamais te deixaria nas horas de tua prova e de teu sofrimento. Quando vistes na areia apenas um par de pegadas, foi exatamente aí que $\mathcal{E} u$ te carreguei nos 6raços."

Pegadas na Areia Autor desconfecido 